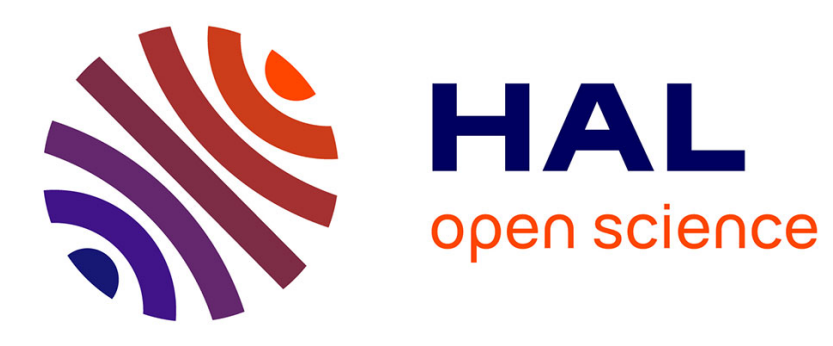

\title{
Motor Preparation of Step Initiation: Error-related Cortical Oscillations
}

\author{
Arnaud Delval, Aurore Braquet, Nauaman Dirhoussi, Madli Bayot, Philippe \\ Derambure, Luc Defebvre, Celine Tard, Kathy Dujardin
}

\section{- To cite this version:}

Arnaud Delval, Aurore Braquet, Nauaman Dirhoussi, Madli Bayot, Philippe Derambure, et al.. Motor Preparation of Step Initiation: Error-related Cortical Oscillations. Neuroscience, 2018, Neuroscience, 393, pp.12-23. 10.1016/j.neuroscience.2018.09.046 . hal-02178934v5

\section{HAL Id: hal-02178934 \\ https://hal.univ-lille.fr/hal-02178934v5}

Submitted on 26 Nov 2020

HAL is a multi-disciplinary open access archive for the deposit and dissemination of scientific research documents, whether they are published or not. The documents may come from teaching and research institutions in France or abroad, or from public or private research centers.
L'archive ouverte pluridisciplinaire HAL, est destinée au dépôt et à la diffusion de documents scientifiques de niveau recherche, publiés ou non, émanant des établissements d'enseignement et de recherche français ou étrangers, des laboratoires publics ou privés. 
Motor preparation of step initiation: error-related cortical oscillations.

Arnaud Delval, 1,2, Aurore Braquet, ${ }^{1,2}$, Nauaman Dirhoussi, 1,2, Madli Bayot, ${ }^{1,2}$, Philippe Derambure, ${ }^{1,2}$, Luc Defebvre, ${ }^{1,2}$, Céline Tard ${ }^{1,2}$, and Kathy Dujardin ${ }^{1,2}$

${ }^{1}$ Univ. Lille, CHU Lille, INSERM, U1171 - Degenerative \& Vascular Cognitive Disorders, F-59000 Lille, France

${ }^{2}$ Lille Centre of Excellence for Neurodegenerative Diseases (LiCEND), F-59000 Lille, France 


\section{Abstract}

Gait initiation can vary as a function of the available and engaged attentional resources. Conflict resolution can disrupt movement preparation and lead to "errors" in motor programming. These "errors" are physiologically useful by enabling us to adapt our motor behavior to situations with conflicting information. The objective of the present study was to analyze the patterns of cortical activation associated with motor programming errors and the corresponding error corrections.

Incongruent flankers around a target arrow were used to trigger errors in anticipatory postural adjustments (APAs) prior to gait initiation; i.e. perturbed motor programming but normal execution. Thirty healthy adults performed a gait initiation task. The event-related potentials (ERPs) and eventrelated desynchronization (ERD) after target presentation were analyzed according to the presence or absence of an APA error.

The ERP was similar in both conditions, except that the Ne and P300 peak latencies were longer for APA errors. Motor programming errors during gait initiation were characterized by longer, less intense low-beta-band ERD over the sensorimotor cortex and alpha ERS followed by stronger alpha ERD during errors.

APA errors were associated with a specific alpha/beta oscillation profile over the sensorimotor cortex; these beta oscillations might be sensitive markers of non-conscious motor error and correction monitoring.

Keywords: cortical activation, gait initiation, posture, inhibition, attention 


\section{Highlights}

- Attention disrupts movement preparation and leads to errors in motor programming.

- Errors are associated with a prolonged beta power decrease over the sensorimotor cortex.

- Alpha/Beta oscillations are sensitive markers of non-conscious motor error monitoring. 


\section{Introduction}

Gait initiation is a motor program characterized by the transition from a static stable stance to a continuously unstable posture during locomotion. The characteristics of gait initiation can vary as a function of the available attentional resources. Indeed, gait initiation can be modulated when the subject is obliged to deal with conflicting information (Uemura et al., 2012). Gait is initiated in two phases: a motor preparation phase (corresponding to anticipatory postural adjustments, APAs) and then an execution phase (corresponding to the time interval between "toe-off" and "heel strike" for the swing leg). During standard gait initiation (i.e. in the absence of external or internal stimuli requiring modulation of the motor program), healthy subjects display a stereotypical APA pattern. Foot-off of the swing leg is preceded by a shift in body weight that displaces the centre of pressure (CoP) backwards and towards the swing leg. Next, the CoP is displaced forwards and towards the stance leg. Hence, APAs create the conditions required for progression (Brenière and Do, 1991). Furthermore, APAs along the mediolateral axis are predictive of postural stability (McIlroy and Maki, 1999). However, it is known that self-triggered gait initiation is not always preceded by an APA (Delval et al., 2014; Lu et al., 2017). The lack of a lateral or posterior APA was nevertheless infrequent (in $2 \%$ of the trials) in healthy elderly controls during externally triggered rapid stepping (Delval et al., 2014). Conversely, the absence of APAs can be frequently observed in patients with freezing of gait and an increased risk of falls (Delval et al., 2014). The occurrence of APA errors can also perturb the gait initiation program by delaying the onset of movement execution (Cohen et al., 2011). This corresponds to the correction of an APA when the initial direction of postural adjustment is not appropriate (for example, when the CoP moves inappropriately towards the stance leg and is then appropriately moved first towards the swing leg and only then towards the stance leg). This APA error corresponds to a motor program error, which is efficiently corrected and prevents incorrect step initiation from taking place. It is known that APA errors are more frequent in conditions modulated by attention (especially in the presence of incongruent stimuli (Uemura et al., 2013) or with invalid cues (Tard et al., 2013)) than in conditions with congruent step initiation stimuli. However, it is not known if and how these APA errors are modulated in the cortex.

Cortical areas involved in gait initiation include the sensorimotor cortex, premotor cortex, basal ganglia and brainstem structures. It was initially suggested that the motor programs underlying the elicitation of gait initiation were stored in subcortical structures, and could be elicited by a startling stimulus or a decision for action (Takakusaki, 2008; Queralt et al., 2010; Delval et al., 2012; Watanabe et al., 2016a). However, studies in patients with focal lesions of the supplementary motor area and studies in patients with Parkinson's disease (Viallet et al., 1992; Gantchev et al., 1996) have shown that APAs can be modulated at the supraspinal level, since the supplementary motor area, the basal ganglia and the pontomedullary reticular formation are linked by neural networks. Moreover, inhibitory repetitive transcranial magnetic stimulation over the supplementary motor area shortens the APA duration for a brief period, i.e. for the first stepping trial after stimulation (Jacobs et al., 2009). The output of this 
pathway is located in the midbrain locomotor region (which may correspond in part to the cuneiform nucleus and the dorsal part of the pedunculopontine nucleus), which is connected to limbic structures and the basal ganglia (Pahapill and Lozano, 2000).

Attentional control can modulate gait initiation - either directly by involving brainstem structures (for example, the alert process induced by a loud stimulus can product a start-react effect) or indirectly via a cortical loop that includes more complex attentional networks (Delval et al., 2012; Tard et al., 2013). Cortical movement preparation can be measured through electroencephalogram (EEG) features like event-related potentials (ERPs) and event-related (de)synchronization (ERD/S). In the frequency domain, ERD (mainly in the alpha and beta bands) is the cortical marker of movement intention. It has been demonstrated that gait initiation is associated with desynchronization of sensorimotor rhythms related to sensorimotor cortex activation (Pfurtscheller and Andrew, 1999). If the EEG is responselocked (i.e. locked to the motor response), a movement-related cortical potential (MRCP) is present before gait initiation or when imagining gait initiation (Vidailhet et al., 1993, 1995). For the gait initiation task, if the EEG is target-locked, the early ERP components are probably influenced by the different physical characteristics of the stimuli (Rektor et al., 2006) and a posterior P300 can be found, higher in case of stimulus driven attention for example (Tard et al., 2013), whereas late components reflect motor preparation (Hamano et al., 1997). More recently, combined ERP and ERD/S recordings via an EEG brain-computer interface were used to detect gait initiation (Jiang et al., 2015; Sburlea et al., 2015).

ERPs are also used to monitor cognitive control of action. During error recognition, a negativity (named the "Error-Related Negativity" (ERN or Ne)) and then a "Positive error-related wave" (Pe) can be observed (for a review, see Wessel and Aron (2017)). The functional significance of ERN was associated with error detection (Falkenstein et al., 1991). Alternatively, the ERN was proposed to reflect conflict resolution due to a finding of the "Correct-Related-Negativity" (CRN) (Vidal et al., 2000; Meckler et al., 2011). However, errors during gait initiation are mostly non-conscious and the presence of an ERN or Pe during an APA error in healthy subjects remains uncertain. For example, Watanabe found similar frontal ERN and CRN in trials with or without APA errors during gait initiation (Watanabe et al., 2016b). The significance of these potentials remains discussed. Indeed, it has been demonstrated that the ERN occurs also after "partial errors", i.e., incorrect activities that are not sufficient to produce overt errors (Carbonnell and Falkenstein, 2006), which is observed during spontaneous correction of APA errors. To date, the cortical areas involved in gait initiation errors have not been extensively studied and the focus was only on $\mathrm{Fz}, \mathrm{FCz}$, and $\mathrm{Cz}$ (Watanabe et al., 2016b). Indeed, the human sensorimotor system needs to be able to rapidly correct for errors in an ongoing motor command brought about by sudden, unexpected changes in the movement environment (such as conflicting information, for example) (Krigolson et al., 2008). The present study was designed to evaluate the cortical changes induced by these adaptive reactions called APA errors. The study's primary objective was to use a combined ERP 
and time-frequency analysis to evaluate cortical activation during correct gait initiation (i.e. with no APA errors) and during disturbed step initiation (i.e. with APA errors). Our starting hypothesis was that APA errors would be associated with ERP modulations featuring error-related potentials (for example, error-related negativity/positivity (Ne/Pe) (Falkenstein et al., 2000)) and/or changes in beta-band ERS, for example increased beta ERS, asobserved in stop-signal paradigms for movements requiring motor inhibition (Duque et al., 2017). Modulations in lower bands (delta-theta) have also been attributed to error monitoring in children, young and elderly adults (Kolev et al., 2001, 2005; Albrecht et al., 2009).

\section{Material and Methods}

\section{Participants}

Thirty healthy adult volunteers (16 females, 14 males; 29 right-handed; mean \pm standard deviation (SD) age: $39.4 \pm 14.2$ years) participated in the study after providing written, informed consent. None of the participants had a history of medication use (neuroleptics, benzodiazepines, etc.) or disease (neurological, orthopaedic or psychiatric) that could have interfered with gait. The mean \pm SD Montreal Cognitive Assessment score (Nasreddine et al., 2005) was $28.5 \pm 2$. Participants with a score of less than 26 out of 30 were excluded. The study was approved by the local independent ethics committee (CPP Nord-Ouest, Lille, France; reference: 2015-A00013-46).

The experimental setting

The participant was told to stand in a stable, comfortable, natural posture on a force platform, with his/her feet parallel and with a gap of a few centimeters between the feet. A computer display screen was placed at head height 1 meter in front of the participant. The attentional task was an adaptation of the attentional network test (Fan et al., 2002) (Figure 1). The participant was instructed to initiate a forward step after presentation of the visual target (an arrow pointing to the right or to the left, which was visible for $1500 \mathrm{~ms}$ ). If the arrow pointed to the left, the participant had to initiate gait with the left foot; conversely, if the arrow pointed to the right, the participant had to initiate gait with the right foot. The balance weight shift between the 2 feet was controlled online (position of the CoP between the 2 feet visualized by the Nexus software). The present study only assessed the condition with incongruent flankers (i.e. flankers pointing in the opposite direction to the target arrow), in which the frequency of APA errors is reportedly higher (Uemura et al., 2013). Indeed, differences in ERP amplitudes have been reported between congruent and incongruent conditions in a similar study design in seated condition (Neuhaus et al., 2010). A total of 144 incongruent trials (out of a total of 300) were available for each participant. 
Motion analysis

Data were collected with a three-dimensional motion analysis system (VICON 370®, Oxford Biometrics, Oxford, UK), using eight infrared cameras and a sampling frequency of $100 \mathrm{~Hz}$. The CoP was measured with two force platforms (the ORG-5 model from AMTI®, Watertown, MA, USA) at a sampling frequency of $1000 \mathrm{~Hz}$. Reflective markers were placed on precise, reproducible, anatomic landmarks on each foot: the toe (the head of the second metatarsal), the lateral malleolus, and the heel. The data were then computed by the same operator using an in-house MATLAB $^{\circledR}$ routine (The MathWorks, Natick, MA, USA).

The direction of the APA was considered to be normal if the CoP moved backwards and sideways towards the swing foot. Conversely, the direction of the APA was considered to be abnormal (i.e. an APA error) if the CoP moved first towards the stance foot and only then towards the swing foot (see Figure 2). The reaction time (RT) was defined as the time interval between the appearance of the target (S2) and the beginning of the APA or $T_{0}$. An RT $<100 \mathrm{~ms}$ was classified as a false start and was excluded from further analyses. Incorrect starts (i.e. starts with the wrong foot) were also excluded. An in-house $\mathrm{MATLAB}^{\circledR}$ routine detected changes in CoP velocity> mean $+3 \mathrm{SD}$ of the baseline period (-1500 -1000 $\mathrm{ms}$ before target stimulus), the experimenter then chose the start of the APAs according to the curves in $\mathrm{X}$ and $\mathrm{Y}$ axis. Toe-off was detected visually (from the toe marker trajectory in the sagittal plane) and then reported on the CoP curve. It corresponded to the time the CoP shifted forwards. The APA duration was assessed by subtracting $T_{0}$ from the toe-off time. For APA errors, the correction time was defined as the time interval between $T_{0}$ and the sideways corrective shift (i.e. the beginning of the APA in the correct direction).

Acquisition of electroencephalographic data

The electroencephalogram (EEG) was recorded with an $\mathrm{Ag} / \mathrm{AgCl}$ 128-scalp-electrode cap (Waveguard®, ANT Neuro, Enschede, The Netherlands), positioned according to the 10/05 international system (Oostenveld and Praamstra, 2001). Data were acquired with $\mathrm{ASA}^{\mathrm{TM}}$ software (ANT Neuro), using a 0.01 to $100 \mathrm{~Hz}$ band-pass filter, a sampling frequency of $512 \mathrm{~Hz}$, and impedances below $20 \mathrm{k} \Omega$. The data were pre-processed with $\mathrm{ASA}^{\mathrm{TM}}$ software in order to reject ocular artifacts and apply a $50 \mathrm{~Hz}$ notch filter to the recordings. Next, interpolation was performed for artifact-affected electrodes, with a maximum interpolation rate of $10 \%(\mathrm{n}=13)$ for the whole set of 128 scalp electrodes. 
The EEG data were then analyzed with Brain Vision Analyzer 2.0 software (BrainProducts). Muscle artifacts were manually removed from the EEG layout; thereafter, we segmented the EEG data into 2500 $\mathrm{ms}$ epochs that were time-locked with respect to target onset (1500 ms before and $1000 \mathrm{~ms}$ afterwards). The median (min-max) number of epochs selected (after artifact rejection) per participant was 49 (2098) for APA errors and 69 (38-107) for normal APAs.

\section{ERP analyses}

ERP were analyzed with the EEGLAB toolbox (Delorme and Makeig, 2004), using a baseline from $1500 \mathrm{~ms}$ before the target onset to $1000 \mathrm{~ms}$ for target-locked ERP and from $1500 \mathrm{~ms}$ before the APA onset to $650 \mathrm{~ms}$ for response-locked ERP. The time window analysis was from S2 to $1000 \mathrm{~ms}$ after target onset. We first analyzed ERP scalp distribution maps. Next, the ERP wave's characteristics were assessed and collected by grand-averaging over the main central electrodes (Fz, Cz, Pz).

For target-locked ERP, we focused on P300 over Pz. For response-locked ERP, we analyzed ERN/CRN over Fz and P300/Pe over Pz. The amplitude of potentials was measured as the difference between the maximum peak of the ERP waveform and the mean baseline voltage (which occurs prior to the stimulus). Latency was defined as the interval between target presentation and the point of highest positive amplitude in the time window of the potential. For target-locked ERP, time window of P300 ranged from 250 to $500 \mathrm{~ms}$ after target presentation. For response-locked ERP, the time window of the ERN/CRN ranged from -50-200 ms after APA start and from 0-400 ms for the posterior component. ERD/ERS analyses

Time-frequency analysis requires computing the power spectrum over a sliding latency window. ERD data were analyzed using EEGLAB software (Delorme and Makeig, 2004) with a $500 \mathrm{~ms}$ baseline (between 1500 and $1000 \mathrm{~ms}$ before the target's appearance, target-locked and response-locked). To characterize event-related EEG oscillations like ERD and ERS, we applied a time-frequency analysis based on a continuous wavelet transform. We used a version of sinusoidal wavelets in which the number of cycles increases slowly with frequency (e.g. 1.5 cycles at $4 \mathrm{~Hz}$, and 5.6 cycles at $30 \mathrm{~Hz}$ ) with a window width of 213 samples (416 ms). This procedure has been described in (Delorme and Makeig, 2004), and similar approaches for time windows of around $2500 \mathrm{~ms}$ have been described in (Fan et al., 2007). Time-frequency analyses were performed between $4-7 \mathrm{~Hz}$ (the theta band), $8-12 \mathrm{~Hz}$ (the alpha band), and $13-30 \mathrm{~Hz}$ (the beta band, divided in a low beta band (13-20 Hz) and a high beta band (20-30 $\mathrm{Hz})$ ).

\section{Cortical sources}


A realistic head model was built by segmenting a template MRI data with Freesurfer software (Dale et al., 1999). The lead field matrix was then computed for a cortical mesh with 15000 vertices, using Brainstorm software (Tadel et al., 2011) and OpenMEEG software (Gramfort et al., 2010). The weighted minimum-norm estimate was then used to reconstruct the cortical sources (using Brainstorm toolbox (Tadel et al., 2011)) in the time window corresponding to motor preparation.

\section{Statistical analyses}

Characteristics of APAs were compared using a one-way ANOVA after checking normality of the distributions. To evaluate differences in cortical activation (ERPs, ERD/S and source localization) in trials with an APA error vs. trials with a normal APA, we used a non-parametric permutation (randomization) test to obtain the p-value for each electrode and each time point (for ERP and ERD/S) and for each source reconstruction. The false discovery rate (FDR) method was used to correct for multiple comparisons (Genovese et al., 2002), and enabled us to determine which electrodes differed between the two conditions at the different time points (scalp maps) and to compare ERD/ERS maps between both conditions. These analyses were performed with the EEGLAB toolbox (Delorme and Makeig, 2004), which includes MATLAB statistical routines at this purpose. For comparisons between source localizations, we used the scripts included in the Brainstorm toolbox (Tadel et al., 2011)). Peak amplitudes and latencies (for P300 on Pz, for example) were compared in a t-test (in SPSS 17 for Windows) after checking the normality of distribution in a Kolmogorov-Smirnov test. The threshold for statistical significance was set to $\mathrm{p}<0.05$ for all analyses.

Results

Behavioral data

In trials with incongruent flankers, the APA error rate was $41.0 \%$.

The false start rate. The false start rate (i.e. RTs $<100 \mathrm{~ms}$ ) was $11.9 \%$. These trials were excluded from further analysis, since they did not correspond to APA errors.

The error step rate. A start with the wrong foot was rare, since it occurred in only $0.56 \%$ of the trials. These trials were excluded from the analysis because they did not correspond to correct error monitoring. The low number of these events prevented us from analyzing them separately.

The mean \pm SD RT was $0.27 \pm 0.08 \mathrm{~s}$ for normal APAs and $0.23 \pm 0.06 \mathrm{~s}$ for APA errors $(\mathrm{p}<0.001)$. The mean \pm SD APA duration was longer for APA errors $(0.64 \pm 0.13 \mathrm{~s})$ than for normal APAs $(0.47 \pm$ 
$0.10 \mathrm{~s})(\mathrm{p}<0.001)$. The mean \pm SD correction time for APA errors was $0.20 \pm 0.07$ s (i.e. $0.43 \pm 0.07 \mathrm{~s}$ after target presentation, on average).

\section{ERP}

Target-locked ERP: as shown in Figure 3, the ERP scalp distribution maps revealed an early anterior component (N2, see discussion), a late central negative component (corresponding to preparation of movement) and a posterior positive component (at the same scalp sites as the P300). There were no differences in the ERP maps between the "APA error" and "normal APA" conditions except for P300 component (see Figures 3 and 4).

The mean \pm SD P300 peak latency (Pz electrode) was longer for the APA error condition than the normal APA condition $(0.50 \pm 0.08$ s vs. $0.47 \pm 0.08$ s, respectively; $\mathrm{p}<0.01)$. No differences in P300 peak amplitude were observed.

Response-locked: in both APA conditions, early negativity (in the time window of ERN or CRN) occurred, later in case of APA error. Late positivity (P300 or Pe, see discussion) also occurred in both conditions, later in case of APA error on posterior regions. The mean \pm SD ERN/CRN peak latency (Fz electrode) was longer for the APA error condition than the normal APA condition ( $0.12 \pm 0.05 \mathrm{~s}$ vs. 0.08 $\pm 0.05 \mathrm{~s}$, respectively; $\mathrm{p}<0.001)$. No differences in peak amplitude were observed. The mean $\pm \mathrm{SD}$ Pe/P300 peak latency (Pz electrode) was longer for the APA error condition than the normal APA condition $(0.26 \pm 0.07 \mathrm{~s}$ vs. $0.19 \pm 0.06 \mathrm{~s}$, respectively; $\mathrm{p}<0.001)$. No differences in peak amplitude were observed.

\section{ERD data}

As shown in Figures 5 and 6, we observed similar theta-band ERS (between 200 and 600 ms, targetlocked; starting at $\mathrm{T} 0$, response-locked) in both conditions.

Alpha ERS was significantly more pronounced in trials with an APA error (starting around $300 \mathrm{~ms}$ after S2, target-locked; during APA, response-locked) and was followed by a stronger alpha ERD (responselocked).

Central beta ERD was observed, starting $200 \mathrm{~ms}$ after S2 (target-locked); or just before T0 (responselocked). This feature lasted significantly longer over $\mathrm{Cz}$ in trials with an APA error (Figure 6). Moreover, beta ERD over the sensorimotor cortex was more attenuated in the low beta band (i.e. 13-20 $\mathrm{Hz}$ ) than in the high beta band $(20-30 \mathrm{~Hz})$ in trials with an APA error (relative to trials with a normal APA) in target-locked analysis (Figures 5 and 6). We can observe that this beta ERD was present during 
both normal APAs and APA errors but was more prolonged (response-locked and target-locked) in case of error.

Cortical sources of changes in the EEG signal during motor programming

Cortical sources in the 0-600 ms time interval (target-locked) are shown in Figure7. Occipital and temporoparietal regions were activated at $200 \mathrm{~ms}$, and then the sensorimotor cortex and the frontal dorsolateral cortex were activated during both normal APAs and APA errors.

\section{Discussion}

Our present results showed that an error in motor programming during gait initiation in healthy subjects was not associated with obvious differences in ERPs. We only observed a longer P300 peak latency in trials with an APA error. However, we observed extended beta ERD over the sensorimotor cortex, and more pronounced alpha ERS followed by an ERD in trials with an APA error.

Are APA errors low-level errors?

It is known that the motor program can be adjusted during APAs. This process might involve rapid, direct sensorimotor loops via visual afferences for stimulus detection and proprioceptive afferences for the ongoing APA. Hence, healthy subjects are able to adjust the motor program after it has started by delaying foot lift until the correct motor program has been selected. Response inhibition - the ability to rapidly cancel an action - is a critical component of executive function. In gait initiation, response inhibition quickly corrected APAs initiated in the wrong direction (around $200 \mathrm{~ms}$ after the start of the APA error (Tard et al., 2015)). This means that subjects can react to the perception of conflicting information and quickly reorient ongoing actions. Many researchers have investigated the neural substrates of behavioral inhibition by applying laboratory tasks based on the stop-signal paradigm and that require a planned action to be stopped (Duque et al., 2017); however, these tasks require complete inhibition of the motor program, rather than just correction (as in APA errors).

Moreover, the different types of errors described in the literature appear to have different neural bases: Hill and Raab (Hill and Raab, 2005) first distinguished the correction of errors induced externally and internal errors generated by the subject itself. Another distinction has been made between low-level errors (i.e. non-conscious, quickly corrected errors) involving posterior regions of the brain, and highlevel errors (i.e. conscious errors that are not always corrected) involving the medial frontal lobe (Krigolson and Holroyd, 2007). The errors in our study would be classified as internal, low-level, since 
the participants were not aware of them; although some participants described "start hesitation" in a few trials, most were unaware of the quickly corrected motor program.

Cortical activations during unexpected events have recently been reviewed (Wessel and Aron, 2017). Most of the relevant studies were based on the use of stop-signal paradigms and fMRI to identify the underlying motor inhibition system. The right inferior frontal cortex, pre-supplementary motor area and subthalamic nucleus (STN) of the basal ganglia are all involved, with downstream effects on the pallidum, thalamus, and primary motor cortex. Indeed, the STN's role has been emphasized by several fMRI studies (Aron and Poldrack, 2006; Li et al., 2008); activity in the STN is greater during both stop successes and stop errors than in "go" trials, and greater for stop errors than for stop successes (Li et al., 2008). These findings suggest that the STN has a role in suppressing thalamocortical output, which thereby blocks motor response execution via a hyperdirect pathway (Aron and Poldrack, 2006). The mechanisms in our paradigm were less clear, since error correction re-oriented a movement rather than stopping it completely as in stop-signal paradigms. Subjects were able to shift their weight toward the swing leg to correct the error. This could correspond to "partial errors", i.e., incorrect activities which are not sufficient to produce overt errors (Carbonnell and Falkenstein, 2006). These latter could produce both ERN and CRN. However, we would have expected more ample negativity over frontal regions in case of APA errors.

\section{Cortical markers of error monitoring}

Evaluating the precise timing of cortical activations requires electrophysiological recordings based on local field potentials or EEG. It is generally thought that an anterior component (ERN/Ne) reflects error inhibition (Kopp et al., 1996), conflict detection (Carter et al., 1998 p.199) or the comparison (response checking) of the neural representation of the actual (erroneous) response and the representation of the required (i.e. correct) response. In our paradigm, however, successful error inhibition was followed by a motor programming correction and then appropriate movement execution. With regard to response checking, the participant had to recognize the engaged motor program (the left or right foot) - usually a non-conscious process - and determine whether or not it corresponded to the appropriate response. This process is much the same in APA errors and normal APAs.

We did not observe any differences in the ERN/CRN amplitudes. The amplitudes of CRN and ERN were also similar for the stepping task in (Watanabe et al., 2016b) who used a Simon task to elicit APA errors. They proposed different interpretations: the more convincing one in our opinion is that APA errors are brief, covert, and are likely corrected by initiating a step with the appropriate leg. As a consequence, ERN amplitude may have become smaller because APA errors were not recognized as definite errors. Once again, this error is not conscious. The late, posterior, positive ERP component observed after presentation of the target is more difficult to interpret. Considering target-locked 
responses, the ERP peaked in the parietal cortex at about $400 \mathrm{~ms}$ (target-locked) and 100-200 ms (response-locked). It might therefore be a P300 component. It is very similar to the response-locked posterior component. The latency (but not the amplitude) differed according to the presence or not of an APA error. The absence of a difference in amplitude was not very surprising because P300's amplitude is primarily modulated by the stimulus's rarity (as in the oddball paradigm). Here, only incongruent targets were considered. They elicited a large P300, regardless of the forthcoming motor preparation (Neuhaus et al., 2010; Deiber et al., 2013). Alternatively, the ERP component might correspond to Pe. The latter is thought to reflect (i) error correction, (ii) a delayed parietal P300 (since it is present in correct trials) or (iii) additional error processing or post-error processing (for a review, see Falkenstein, 2010). Here, the distribution is posterior and not anterior. Moreover, in our paradigm, there were no amplitude differences between trials with and without APA errors. It must be born in mind that the variability in Pe depends on error detectability: the larger the difference between the representations (i.e. the easier the error is to detect), the larger and/or earlier the Pe. There are several possible explanations for the lack of difference in the amplitude of Pe. The participant was not given any information about APA error monitoring. Indeed, both $\mathrm{Ne}$ and $\mathrm{Pe}$ are closely related to conscious perception of the error (Nieuwenhuis et al., 2001; Charles et al., 2013). In fact, in the work by Charles et al., the ERN was absent only when subjects reported that they did not see the target. That was not the case in our study since subjects well identified the target (no error of step side).

Instructing the participant to pay attention (or not) to the error stimulus (Ramautar et al., 2006) can also amplify the ERP. In Ramautar et al.'s study, Pe was much more pronounced for perceived errors than for unperceived errors. We suggest that these ERPs reflect cognitive processing of the stimulus (i.e. incongruent flankers surrounding the arrow) more than perception of the APA error. These scalp ERPs did not seem to be relevant for studying the non-conscious monitoring of an ongoing action, when the error was corrected online before the possible erroneous outcome (i.e. initiation with the wrong foot). According to Krigolson and Holroyd, the P300 component has a role in the online control process for low-level errors (Krigolson and Holroyd, 2007). In a corrective limb adjustment task using a joystick (in which the target's location changed unexpectedly following movement onset, in order to elicit errors), the researchers concluded that if $\mathrm{P} 300$ arises after behavioral changes associated with the online control of movement, then it cannot be involved in the evaluation of target errors (Krigolson et al., 2008). Indeed, the P300 started after the participants had begun to adjust their motor output to accommodate the target perturbation. Moreover, Krigolson and Holroyd did not observe a difference in amplitude according to the presence or absence of correction. As suggested by Krigolson et al. (Krigolson et al., 2008), we hypothesize that P300 reflects the updating of an internal model of the movement environment - processing of flankers, for example (Donchin and Coles, 1988).

Time-frequency analysis and motor programming 
Non-phase-locked (induced) changes can be studied in a time-frequency analysis, which highlights the cortical oscillations related to an external or internal event (Rektor et al., 2006). Indeed, motor-related cortical oscillations are generally assessed by quantifying increases or suppressions in spectral power. For example, increases in amplitude of the cortical oscillations in the delta band $(2-4 \mathrm{~Hz})$ and the gamma (bands 60-200 Hz) are observed during both the planning and execution of movement (Combrisson et al., 2017). The initiation of voluntary movements has also been linked to desynchronization of cortical activity in the alpha band $(8-12 \mathrm{~Hz})$ and the beta band $(13-30 \mathrm{~Hz})$ in electrocorticography and scalp EEG recordings (and then decrease of amplitude of oscillations in the corresponding frequency band) over the motor and premotor cortex (Pfurtscheller, 1981; Neuper et al., 2006).

Firstly, we observed theta synchronization and a more pronounced alpha synchronization in case of error. Secondly, beta ERD was observed over sensorimotor cortex.

Theta-band ERS is linked to an alert effect (Luu et al., 2004) and to stimuli monitoring and discrimination (Wang et al., 2005) engaged in attentional processes (Luu et al., 2004; Fan et al., 2007; Song et al., 2014). Alpha ERS (coupled with theta ERS) at the start of APAs was followed by stronger posterior alpha ERD in case of APA error. This particular pattern has been previously described during different variants of the Simon task during errors in an upper limb task (van Driel et al., 2012) and seems consistent. These patterns according to the variants of the attentional task (in terms of amplitude, location, coupling between different cortical regions) were influenced by performance monitoring (theta ERS), error speed processing (posterior alpha ERD) (van Driel et al., 2012). Increasing alpha ERS is supposed to facilitate the goal-directed behavior (Dockree et al., 2007) by reflecting active mechanisms of sensory suppression for irrelevant-task stimulus (Foxe and Snyder, 2011) which could be particularly useful for proper motor execution in case of APA errors triggered by incongruent stimuli. Then, alpha ERD (response-locked) is strongly associated to visual perception and involved in task anticipation to modulate the excitability in human parieto-occipital cortex (Capotosto et al., 2017). Alpha ERD is therefore stronger in trials with APA errors in order to facilitate the modulation of the sensorimotor cortex with stimulus' perception. It signs the further orientation and maintenance of visual attention (posterior predominant, engagement of parieto-occipital areas (Foxe et al., 1998)).

Beta ERD is thought to reflect the activation of regions engaged in visuospatial attention or motor execution (Pfurtscheller and Lopes da Silva, 1999). During tasks requiring attention, significant increases in the delta, theta and gamma bands have been reported during the planning phase and especially during execution. In contrast, alpha, beta and low-gamma power falls after an execution cue (Combrisson et al., 2017). In our paradigm, the occurrence of beta ERD following the appearance of the target was consistent with this pattern. Oscillations in the beta and gamma bands during motor preparation have been studied in paradigms that compare successful stops with unsuccessful stops (Swann et al., 2009, 2012). Overall, brief beta ERS is followed by longer beta ERD. The latter is more pronounced in successful stop trials. These findings provide insight into our results - even though our study did not feature successful vs. unsuccessful stops. In trials with APA errors, we observed prolonged 
beta ERD over the sensorimotor cortex; this probably reflected the fact that movement preparation was longer when an APA error occurred (Cohen et al., 2011). We also observed less intense low beta ERD during APA errors. In a study evaluating a shifting cognitive task during gait (Wagner et al., 2016), two different beta oscillations were noted: beta ERD (expressing motor execution and motor readiness related to gait movements) and a frontal beta ERS (related to cognitive top-down control on gait). The less intense ERD in the APA error condition might be due to the summation of concomitant ERD (for movement preparation) and ERS (for the cognitive load, with a complicated process for conflict resolution and correction of the engaged motor program). Furthermore, beta frequency oscillations are associated with the maintenance of the "status quo", such as holding a fixed position. In the event of an APA error, the status quo is disrupted. For example, stabilized gait on treadmill is characterized by betaband desynchronization that lasts for at least 15 steps (Wagner et al., 2016). Here, the presence of differences in low beta ERD during an APA error suggested that the status quo had been disrupted (Engel and Fries, 2010). However, low beta modulations have been studied more frequently in cognitive tasks (including memory tasks) than in motor tasks. Other spectral properties (such as phase and phaseamplitude coupling) have also been shown to carry information with regard to the oscillatory dynamics underlying motor processes, and an analysis of these variables might be of value in studying network dynamics during low-level errors (Combrisson et al., 2017). There was a contradiction between the findings of ERN and theta/alpha ERD/S. Contrary to ERP, alpha synchronization appeared in this study to be more sensitive, probably because of its time resolution and the relative specificity of the different frequency bands to monitor brief covert errors such as APA errors. Indeed, previous studies (Kolev et al., 2005, 2005; Albrecht et al., 2009) found modulations in low frequencies band (delta, theta) and ERN in different paradigms (choice reaction task, flankers...) provoking overt errors in different populations but once again, APA errors are of different nature.

\section{Limitations:}

There is a strong relationship between the ERP and ERD/ERS. However, ERD and ERS are not systematically time-locked to the target ERP. Theta- and delta-band ERSs correspond most closely to N200 and P300, respectively (Huster et al., 2013). In fact, an increase in the amplitude of P300 is invariably associated with an increase in power in the low-frequency bands - as observed in the present study. Removing or not the ERP signal of the time-frequency analysis is still subject to debate. In a nonpresented analysis, we removed the ERP signal from the EEG before performing event-related spectral analysis in the beta band; this enabled us to study the induced response alone and not the evoked response: no clear differences (topographical or statistical maps) were observed after the removal.

The attention network task enabled the study of different components of attention (Fan et al., 2002). However, trials with cues might influence the RTs or the proportion of pre-APAs (i.e. APAs occurring 
between the cue and the target presentation but not followed by a step, with a return to the baseline posture at the moment of target presentation (Tard et al., 2015)); however, the proportions of valid, invalid cued and uncued trials did not differ after removal of trials with artifacts. The proportion of no cue trials was $17.8 \%$ (normal APA) vs. $16.7 \%$ (APA error) vs $16.3 \%$ (before removal of trials with artifacts), the proportion of neutral cue trials was $19.3 \%$ (normal APA) vs. $18.2 \%$ (APA error) vs. $20.3 \%$ (before removal of trials with artifacts), the proportion of valid cue trials was $47.5 \%$ (normal APA) vs. $47.4 \%$ (APA error) vs. $47.3 \%$ (before removal of trials with artifacts), the proportion of invalid cue trials was $15.4 \%$ (normal APA) vs $17.6 \%$ (APA error) vs. $16 \%$ (before removal of trials with artifacts). Furthermore, we excluded false start trials (i.e. those with an RT $<100 \mathrm{~ms}$ ). The median number of trials by subject/condition after removal of artifacts was 49 (20-98) for APA errors and 69 (38-107) for normal APAs. One subject has a very low number of trials taken into account but the ERP was clearly identifiable in this particular case. The subject was thus not excluded.

Our present results highlighted a cortical marker of gait initiation APA errors in healthy subjects. Differences in sensorimotor activation (reflected by differing alpha/beta-band ERS/ERD patterns) were observed during APA errors. It remains to be seen how these cortical oscillations are influenced by cortical-subcortical loops. Future research should consider the role of the basal ganglia (and specifically the STN) in movement inhibition. In contrast to ERP analysis, time-frequency methods are useful for monitoring non-conscious errors. These methods could also be used to monitor motor programming errors (in patients with dysexecutive syndrome, for example), and could be implemented in braincomputer interface algorithms. 
Albrecht B, Heinrich H, Brandeis D, Uebel H, Yordanova J, Kolev V, Rothenberger A, Banaschewski T (2009) Flanker-Task in Children: Time-Frequency Analyses of Response Monitoring. J Psychophysiol 23:183-190.

Aron AR, Poldrack RA (2006) Cortical and Subcortical Contributions to Stop Signal Response Inhibition: Role of the Subthalamic Nucleus. J Neurosci 26:2424-2433.

Brenière Y, Do MC (1991) Control of gait initiation. J Mot Behav 23:235-240.

Capotosto P, Baldassarre A, Sestieri C, Spadone S, Romani GL, Corbetta M (2017) Task and Regions Specific Top-Down Modulation of Alpha Rhythms in Parietal Cortex. Cereb Cortex N Y N 1991 27:4815-4822.

Carbonnell L, Falkenstein M (2006) Does the error negativity reflect the degree of response conflict? Brain Res 1095:124-130.

Carter CS, Braver TS, Barch DM, Botvinick MM, Noll D, Cohen JD (1998) Anterior cingulate cortex, error detection, and the online monitoring of performance. Science 280:747-749.

Charles L, Van Opstal F, Marti S, Dehaene S (2013) Distinct brain mechanisms for conscious versus subliminal error detection. Neurolmage 73:80-94.

Cohen RG, Nutt JG, Horak FB (2011) Errors in Postural Preparation Lead to Increased Choice Reaction Times for Step Initiation in Older Adults. J Gerontol A Biol Sci Med Sci Available at: http://www.ncbi.nlm.nih.gov/pubmed/21498431 [Accessed June 10, 2011].

Combrisson E, Perrone-Bertolotti M, Soto JL, Alamian G, Kahane P, Lachaux J-P, Guillot A, Jerbi K (2017) From intentions to actions: Neural oscillations encode motor processes through phase, amplitude and phase-amplitude coupling. Neurolmage 147:473-487.

Dale AM, Fischl B, Sereno MI (1999) Cortical surface-based analysis. I. Segmentation and surface reconstruction. Neurolmage 9:179-194.

Deiber M-P, Ibañez V, Missonnier P, Rodriguez C, Giannakopoulos P (2013) Age-associated modulations of cerebral oscillatory patterns related to attention control. Neurolmage 82:531-546.

Delorme A, Makeig S (2004) EEGLAB: an open source toolbox for analysis of single-trial EEG dynamics including independent component analysis. J Neurosci Methods 134:9-21.

Delval A, Dujardin K, Tard C, Devanne H, Willart S, Bourriez J-L, Derambure P, Defebvre L (2012) Anticipatory postural adjustments during step initiation: elicitation by auditory stimulation of differing intensities. Neuroscience 219:166-174.

Delval A, Moreau C, Bleuse S, Tard C, Ryckewaert G, Devos D, Defebvre L (2014) Auditory cueing of gait initiation in Parkinson's disease patients with freezing of gait. Clin Neurophysiol Off J Int Fed Clin Neurophysiol 125:1675-1681.

Dockree PM, Kelly SP, Foxe JJ, Reilly RB, Robertson IH (2007) Optimal sustained attention is linked to the spectral content of background EEG activity: greater ongoing tonic alpha (approximately $10 \mathrm{~Hz}$ ) power supports successful phasic goal activation. Eur J Neurosci 25:900-907. 
Donchin E, Coles MGH (1988) Is the P300 component a manifestation of context updating? Behav Brain Sci 11:357-374.

Duque J, Greenhouse I, Labruna L, Ivry RB (2017) Physiological Markers of Motor Inhibition during Human Behavior. Trends Neurosci 40:219-236.

Engel AK, Fries P (2010) Beta-band oscillations--signalling the status quo? Curr Opin Neurobiol 20:156-165.

Falkenstein M, Hohnsbein J, Hoormann J, Blanke L (1991) Effects of crossmodal divided attention on late ERP components. II. Error processing in choice reaction tasks. Electroencephalogr Clin Neurophysiol 78:447-455.

Falkenstein M, Hoormann J, Christ S, Hohnsbein J (2000) ERP components on reaction errors and their functional significance: a tutorial. Biol Psychol 51:87-107.

Fan J, Byrne J, Worden MS, Guise KG, McCandliss BD, Fossella J, Posner MI (2007) The relation of brain oscillations to attentional networks. J Neurosci Off J Soc Neurosci 27:6197-6206.

Fan J, McCandliss BD, Sommer T, Raz A, Posner MI (2002) Testing the efficiency and independence of attentional networks. J Cogn Neurosci 14:340-347.

Foxe JJ, Simpson GV, Ahlfors SP (1998) Parieto-occipital approximately $10 \mathrm{~Hz}$ activity reflects anticipatory state of visual attention mechanisms. Neuroreport 9:3929-3933.

Foxe JJ, Snyder AC (2011) The Role of Alpha-Band Brain Oscillations as a Sensory Suppression Mechanism during Selective Attention. Front Psychol 2:154.

Gantchev N, Viallet F, Aurenty R, Massion J (1996) Impairment of posturo-kinetic co-ordination during initiation of forward oriented stepping movements in parkinsonian patients. Electroencephalogr Clin Neurophysiol 101:110-120.

Genovese CR, Lazar NA, Nichols T (2002) Thresholding of statistical maps in functional neuroimaging using the false discovery rate. Neurolmage 15:870-878.

Gramfort A, Papadopoulo T, Olivi E, Clerc M (2010) OpenMEEG: opensource software for quasistatic bioelectromagnetics. Biomed Eng Online 9:45.

Hamano T, Lüders HO, Ikeda A, Collura TF, Comair YG, Shibasaki H (1997) The cortical generators of the contingent negative variation in humans: a study with subdural electrodes. Electroencephalogr Clin Neurophysiol 104:257-268.

Hill H, Raab M (2005) Analyzing a complex visuomotor tracking task with brain-electrical event related potentials. Hum Mov Sci 24:1-30.

Huster RJ, Enriquez-Geppert S, Lavallee CF, Falkenstein M, Herrmann CS (2013) Electroencephalography of response inhibition tasks: functional networks and cognitive contributions. Int J Psychophysiol Off J Int Organ Psychophysiol 87:217-233.

Jacobs JV, Lou JS, Kraakevik JA, Horak FB (2009) The supplementary motor area contributes to the timing of the anticipatory postural adjustment during step initiation in participants with and without Parkinson's disease. Neuroscience 164:877-885. 
Jiang N, Gizzi L, Mrachacz-Kersting N, Dremstrup K, Farina D (2015) A brain-computer interface for single-trial detection of gait initiation from movement related cortical potentials. Clin Neurophysiol 126:154-159.

Kolev V, Falkenstein M, Yordanova J (2005) Aging and Error Processing: Time-Frequency Analysis of Error-Related Potentials. J Psychophysiol 19:289-297.

Kolev V, Yordanova J, Schürmann M, Başar E (2001) Increased frontal phase-locking of event-related alpha oscillations during task processing. Int J Psychophysiol Off J Int Organ Psychophysiol 39:159-165.

Kopp B, Rist F, Mattler U (1996) N200 in the flanker task as a neurobehavioral tool for investigating executive control. Psychophysiology 33:282-294.

Krigolson OE, Holroyd CB (2007) Hierarchical error processing: different errors, different systems. Brain Res 1155:70-80.

Krigolson OE, Holroyd CB, Gyn GV, Heath M (2008) Electroencephalographic correlates of target and outcome errors. Exp Brain Res 190:401-411.

Li C-SR, Yan P, Sinha R, Lee T-W (2008) Subcortical processes of motor response inhibition during a stop signal task. Neurolmage 41:1352-1363.

Lu C, Amundsen Huffmaster SL, Harvey JC, MacKinnon CD (2017) Anticipatory postural adjustment patterns during gait initiation across the adult lifespan. Gait Posture 57:182-187.

Luu P, Tucker DM, Makeig S (2004) Frontal midline theta and the error-related negativity: neurophysiological mechanisms of action regulation. Clin Neurophysiol Off J Int Fed Clin Neurophysiol 115:1821-1835.

Mcllroy WE, Maki BE (1999) The control of lateral stability during rapid stepping reactions evoked by antero-posterior perturbation: does anticipatory control play a role? Gait Posture 9:190-198.

Meckler C, Allain S, Carbonnell L, Hasbroucq T, Burle B, Vidal F (2011) Executive control and response expectancy: A Laplacian ERP study. Psychophysiology 48:303-311.

Nasreddine ZS, Phillips NA, Bédirian V, Charbonneau S, Whitehead V, Collin I, Cummings JL, Chertkow $\mathrm{H}$ (2005) The Montreal Cognitive Assessment, MoCA: a brief screening tool for mild cognitive impairment. J Am Geriatr Soc 53:695-699.

Neuhaus AH, Urbanek C, Opgen-Rhein C, Hahn E, Ta TMT, Koehler S, Gross M, Dettling M (2010) Event-related potentials associated with Attention Network Test. Int J Psychophysiol Off J Int Organ Psychophysiol 76:72-79.

Neuper C, Wörtz M, Pfurtscheller G (2006) ERD/ERS patterns reflecting sensorimotor activation and deactivation. Prog Brain Res 159:211-222.

Nieuwenhuis S, Ridderinkhof KR, Blom J, Band GP, Kok A (2001) Error-related brain potentials are differentially related to awareness of response errors: evidence from an antisaccade task. Psychophysiology 38:752-760.

Oostenveld R, Praamstra P (2001) The five percent electrode system for high-resolution EEG and ERP measurements. Clin Neurophysiol Off J Int Fed Clin Neurophysiol 112:713-719. 
Pahapill PA, Lozano AM (2000) The pedunculopontine nucleus and Parkinson's disease. Brain J Neurol 123 ( Pt 9):1767-1783.

Pfurtscheller G (1981) Central beta rhythm during sensorimotor activities in man. Electroencephalogr Clin Neurophysiol 51:253-264.

Pfurtscheller G, Andrew C (1999) Event-Related changes of band power and coherence: methodology and interpretation. J Clin Neurophysiol Off Publ Am Electroencephalogr Soc 16:512-519.

Pfurtscheller G, Lopes da Silva FH (1999) Event-related EEG/MEG synchronization and desynchronization: basic principles. Clin Neurophysiol Off J Int Fed Clin Neurophysiol 110:1842-1857.

Queralt A, Valls-Solé J, Castellote JM (2010) Speeding up gait initiation and gait-pattern with a startling stimulus. Gait Posture 31:185-190.

Ramautar JR, Kok A, Ridderinkhof KR (2006) Effects of stop-signal modality on the N2/P3 complex elicited in the stop-signal paradigm. Biol Psychol 72:96-109.

Rektor I, Sochůrková D, Bocková M (2006) Intracerebral ERD/ERS in voluntary movement and in cognitive visuomotor task. Prog Brain Res 159:311-330.

Sburlea Al, Montesano L, de la Cuerda RC, Alguacil Diego IM, Miangolarra-Page JC, Minguez J (2015) Detecting intention to walk in stroke patients from pre-movement EEG correlates. J NeuroEngineering Rehabil 12:113.

Song K, Meng M, Chen L, Zhou K, Luo H (2014) Behavioral Oscillations in Attention: Rhythmic $\alpha$ Pulses Mediated through $\theta$ Band. J Neurosci Off J Soc Neurosci 34:4837-4844.

Swann N, Tandon N, Canolty R, Ellmore TM, McEvoy LK, Dreyer S, DiSano M, Aron AR (2009) Intracranial EEG Reveals a Time- and Frequency-Specific Role for the Right Inferior Frontal Gyrus and Primary Motor Cortex in Stopping Initiated Responses. J Neurosci 29:1267512685.

Swann NC, Cai W, Conner CR, Pieters TA, Claffey MP, George JS, Aron AR, Tandon N (2012) Roles for the pre-supplementary motor area and the right inferior frontal gyrus in stopping action: electrophysiological responses and functional and structural connectivity. Neurolmage 59:2860-2870.

Tadel F, Baillet S, Mosher JC, Pantazis D, Leahy RM (2011) Brainstorm: a user-friendly application for MEG/EEG analysis. Comput Intell Neurosci 2011:879716.

Takakusaki K (2008) Forebrain control of locomotor behaviors. Brain Res Rev 57:192-198.

Tard C, Dujardin K, Bourriez J-L, Derambure P, Defebvre L, Delval A (2013) Stimulus-driven attention modulates the release of anticipatory postural adjustments during step initiation. Neuroscience 247C:25-34.

Tard C, Dujardin K, Girard A, Debaughrien M, Derambure P, Defebvre L, Delval A (2015) How does visuospatial attention modulate motor preparation during gait initiation? Exp Brain Res.

Uemura K, Oya T, Uchiyama Y (2013) Effects of visual interference on initial motor program errors and execution times in the choice step reaction. Gait Posture 38:68-72. 
Uemura K, Yamada M, Nagai K, Shinya M, Ichihashi N (2012) Effect of dual-tasking on the center of pressure trajectory at gait initiation in elderly fallers and non-fallers. Aging Clin Exp Res 24:152-156.

van Driel J, Ridderinkhof KR, Cohen MX (2012) Not all errors are alike: theta and alpha EEG dynamics relate to differences in error-processing dynamics. J Neurosci Off J Soc Neurosci 32:1679516806.

Viallet F, Massion J, Massarino R, Khalil R (1992) Coordination between posture and movement in a bimanual load lifting task: putative role of a medial frontal region including the supplementary motor area. Exp Brain Res Exp Hirnforsch Expérimentation Cérébrale 88:674684.

Vidailhet M, Atchison PR, Stocchi F, Thompson PD, Rothwell JC, Marsden CD (1995) The bereitschaftspotential preceding stepping in patients with isolated gait ignition failure. Mov Disord Off J Mov Disord Soc 10:18-21.

Vidailhet M, Stocchi F, Rothwell JC, Thompson PD, Day BL, Brooks DJ, Marsden CD (1993) The Bereitschaftspotential preceding simple foot movement and initiation of gait in Parkinson's disease. Neurology 43:1784-1788.

Vidal F, Hasbroucq T, Grapperon J, Bonnet M (2000) Is the "error negativity" specific to errors? Biol Psychol 51:109-128.

Wagner J, Makeig S, Gola M, Neuper C, Müller-Putz G (2016) Distinct $\beta$ Band Oscillatory Networks Subserving Motor and Cognitive Control during Gait Adaptation. J Neurosci 36:2212-2226.

Wang C, Ulbert I, Schomer DL, Marinkovic K, Halgren E (2005) Responses of human anterior cingulate cortex microdomains to error detection, conflict monitoring, stimulus-response mapping, familiarity, and orienting. J Neurosci Off J Soc Neurosci 25:604-613.

Watanabe T, Ishida K, Tanabe S, Nojima I (2016a) Preparatory state and postural adjustment strategies for choice reaction step initiation. Neuroscience 332:140-148.

Watanabe T, Tsutou K, Saito K, Ishida K, Tanabe S, Nojima I (2016b) Performance monitoring and response conflict resolution associated with choice stepping reaction tasks. Exp Brain Res 234:3355-3365.

Wessel JR, Aron AR (2017) On the Globality of Motor Suppression: Unexpected Events and Their Influence on Behavior and Cognition. Neuron 93:259-280. 
Figure 1. Attentional Network test

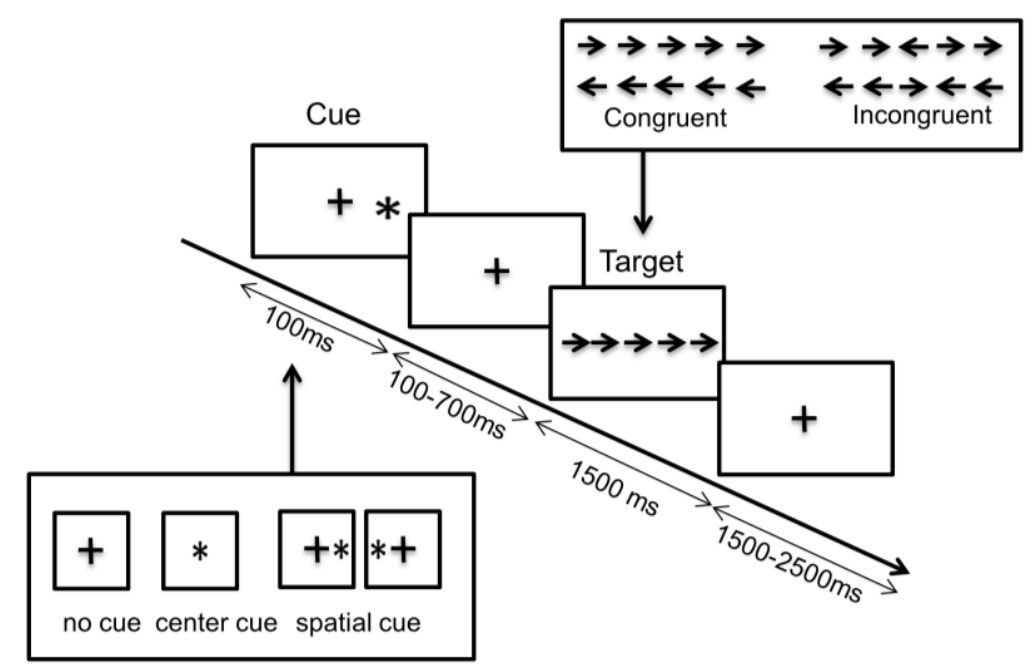

A schematic diagram of the attentional task. S1: cue; S2: target. The target appeared for $1500 \mathrm{~ms}$ and was surrounded by flankers (four arrows: two on each side) that were either congruent or incongruent. The targets could be preceded by valid or invalid spatial cues, i.e. asterisks indicating (or not) the direction of the arrow. Four blocks of 75 trials were administered. The blocks were separated by short breaks of variable duration. The cue and target conditions were presented in a pseudo-random order: 156 congruent trials, 144 incongruent trials, 49 trials with no cue, 61 trials with a central cue, and 190 trials with a spatial cue (142 valid and 48 invalid cues). Only incongruent trials were analyzed in the present study. The proportion of no cue trials was $16.3 \%$, the proportion of neutral cue trials was $20.3 \%$, the proportion of valid cue trials was $47.3 \%$, and the proportion of invalid cue trials was $16 \%$.

Figure 2. Normal Anticipatory Postural Adjustments (APA) and APA error. 


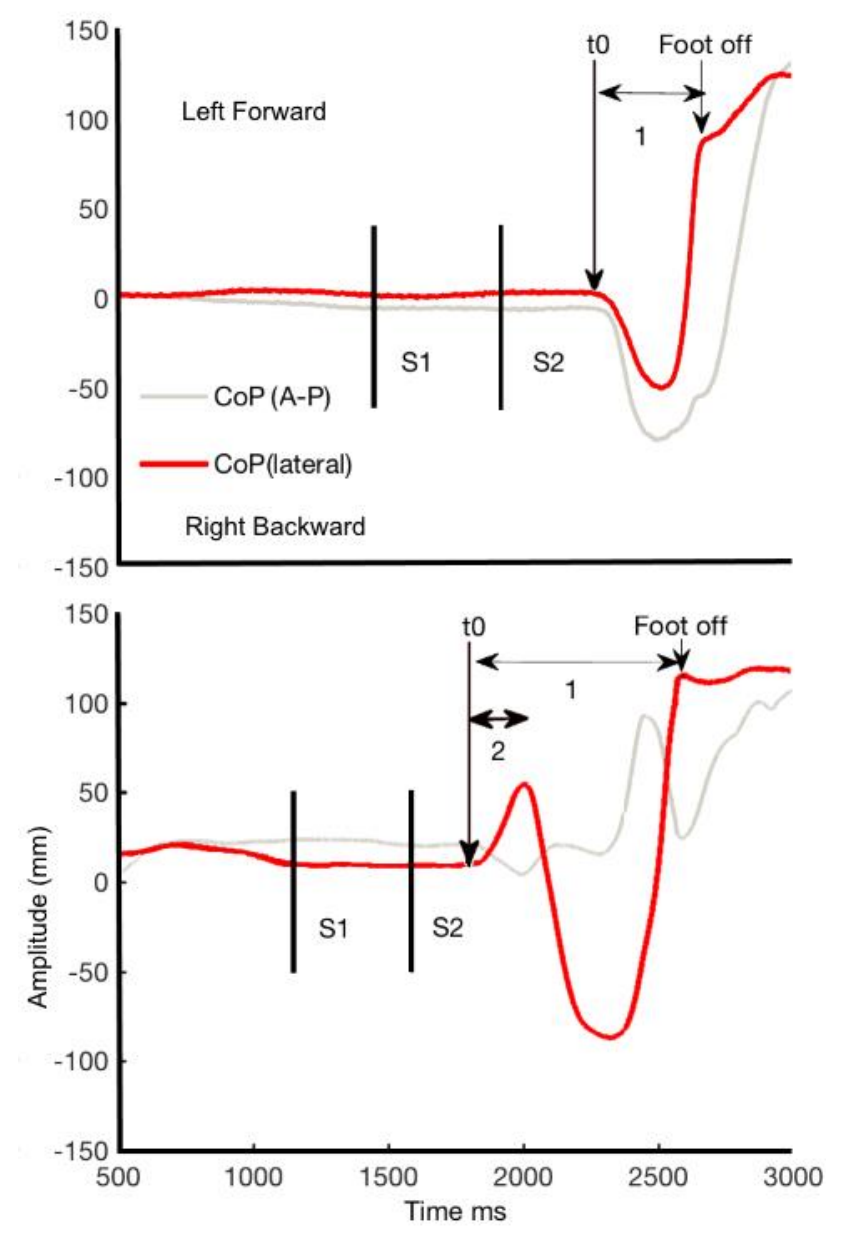

Step initiation with the right foot by a study participant. Top panel: a normal APA, where the center of pressure (CoP) shifts to the swing leg (right) and then to the stance leg (left) (lateral CoP: red line). Bottom panel: an APA error: the CoP shifts towards the stance leg (left) but the trajectory is corrected;

Figure 3. Event-related potentials in normal Anticipatory Postural Adjustments (APA) and APA error. 

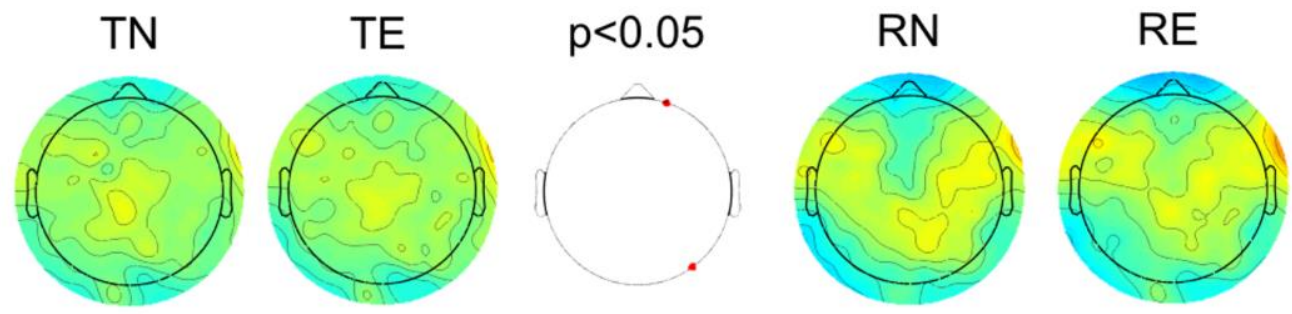

$\mathrm{p}<0.05$

$0-100 \mathrm{~ms}$
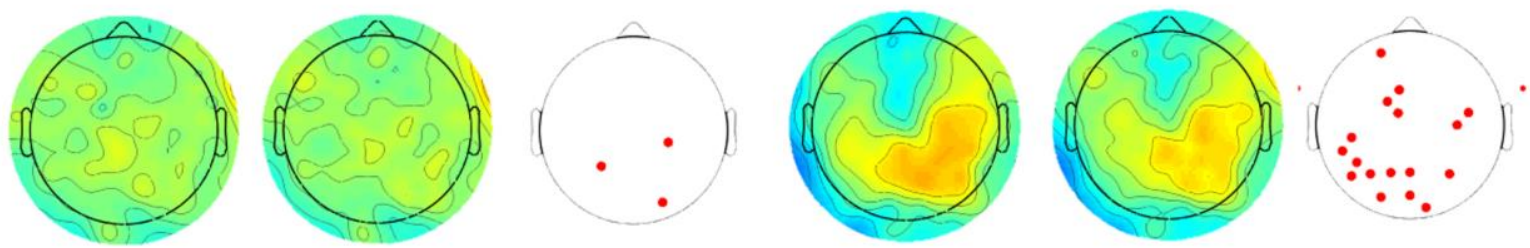

$100-200 \mathrm{~ms}$
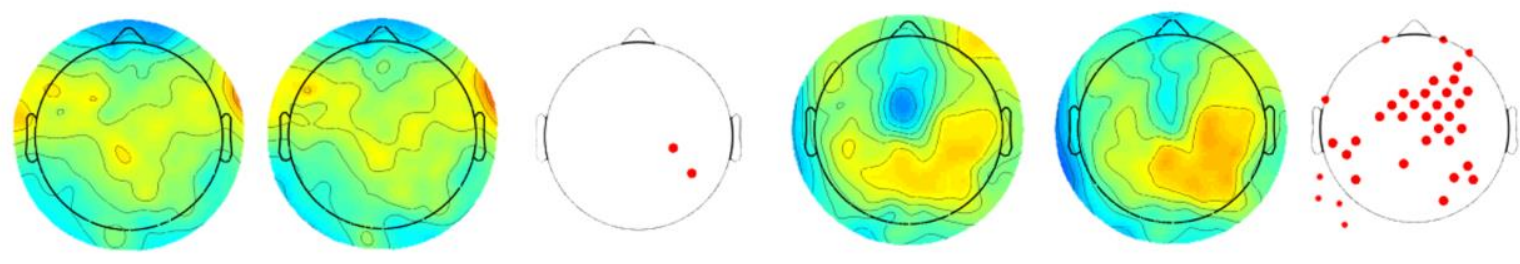

200-300 ms
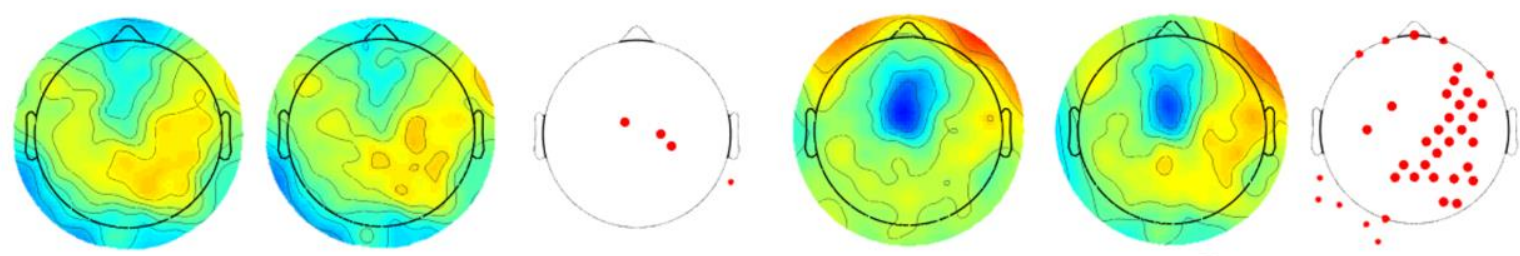

$300-400 \mathrm{~ms}$
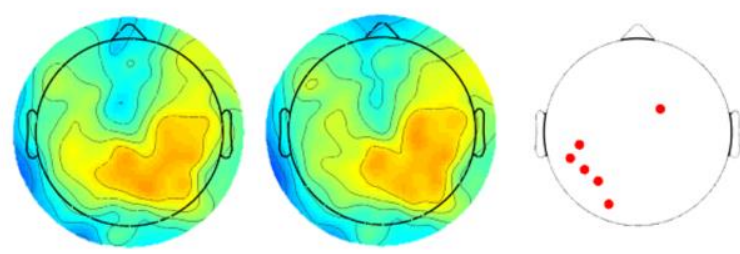

400-500 ms
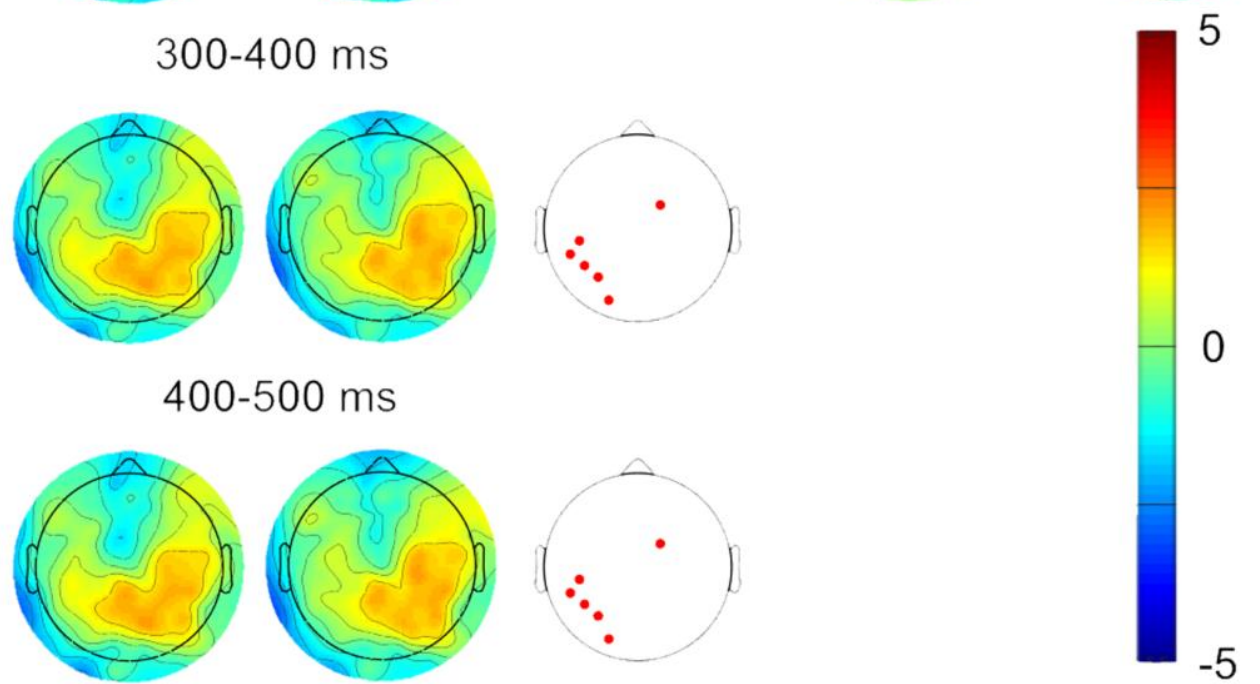

$500-600 \mathrm{~ms}$

Top view of topographic voltage maps for each condition (i.e. a normal APA-N- or an APA error-E-). $O$ ms corresponds to either the target presentation (S2), target-locked (T), or to the start of the APAs (response-locked:R). Cold and hot colors correspond to negative and positive ERPs, respectively. Red dots correspond to electrodes with differences between conditions (whatever the direction), as indicated by permutation tests with FDR correction. 
Figure 4. Event-related potentials in normal Anticipatory Postural Adjustments (APA) and APA error in midline derivations.
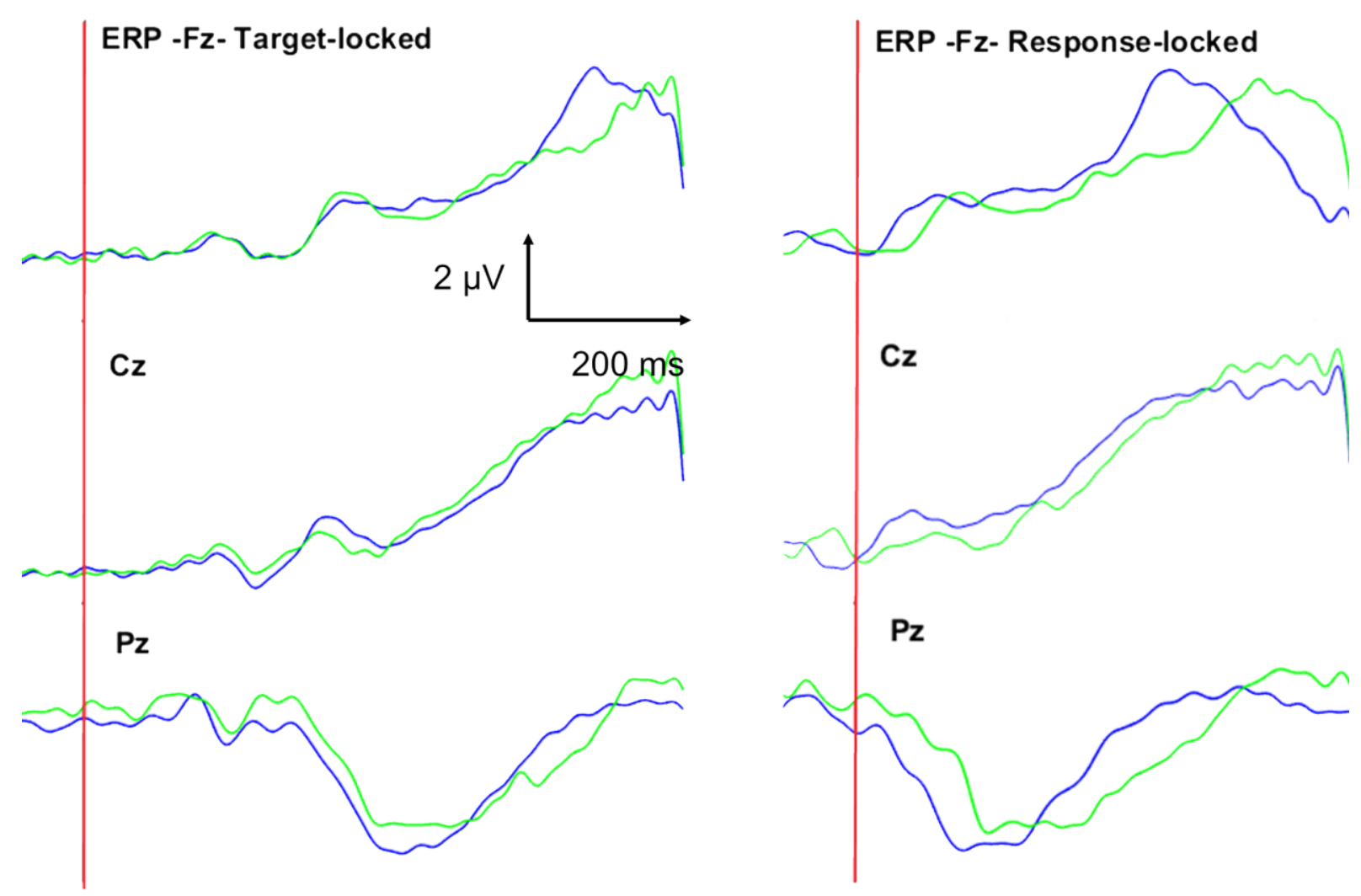

ERP for $F z, C z$ and Pz sites in two conditions: blue: grand average of normal APA vs. green, grand average of APA error. 0 ms corresponds to either the target presentation (S2), target-locked, or to the start of the APAs (response-locked). Target-locked: P300 occurred later in case of APA error. Response-locked: negative components (?Ne and CRN) were observed, later in case of APA error. P300 or Pe occurred later in case of APA error.

Figure 5. Event-related desynchronization/synchronization (ERD/ERS) in normal Anticipatory Postural Adjustments (APA) and APA error. 


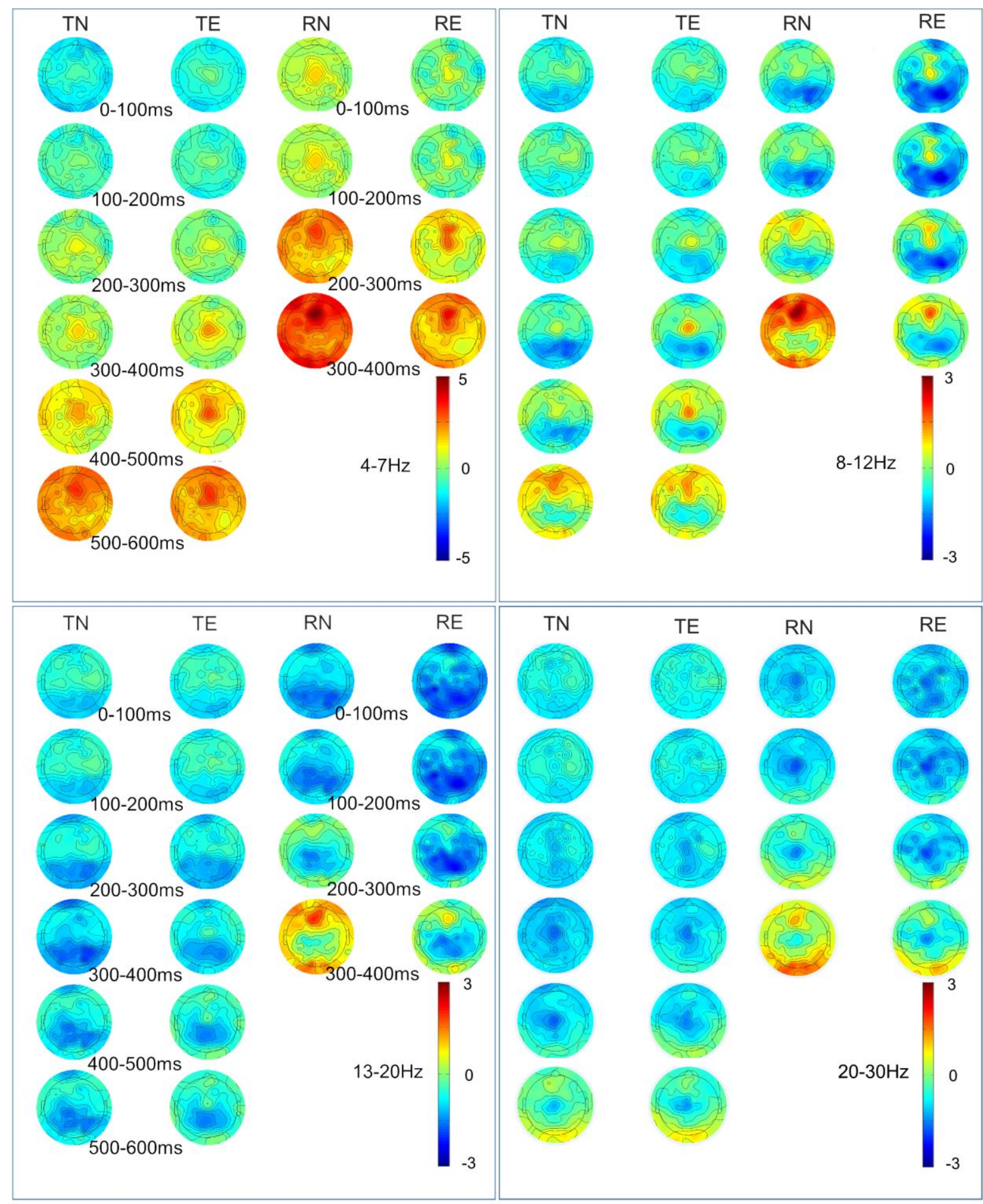

Top view of spectral maps (in $\mathrm{dB}$ ) in the 4-7 Hz, 8-12 Hz, 13-20 Hz and 20-30 Hz bands for normal APAs $(N)$ and APA errors $(E)$. Target-locked $(T)$ and response-locked $(R)$ are shown. 0 ms correspond either to the target presentation or to TO (start of the APAs). The color at each image pixel indicates the power (in $d B$ ) of a given frequency band. Hot colors correspond to an increase in power relative to the baseline, and cold colors correspond to a decrease in power. Theta, alpha ERS were observed in both conditions after target presentation. Beta ERD was observed in both conditions but was more prolonged for APA errors. The low beta ERD was less intense for APA errors (target-locked only). 
Figure 6. Event-related desynchronization/synchronization (ERD/ERS) in normal Anticipatory Postural Adjustments (APA N) and APA error (E) over Cz.

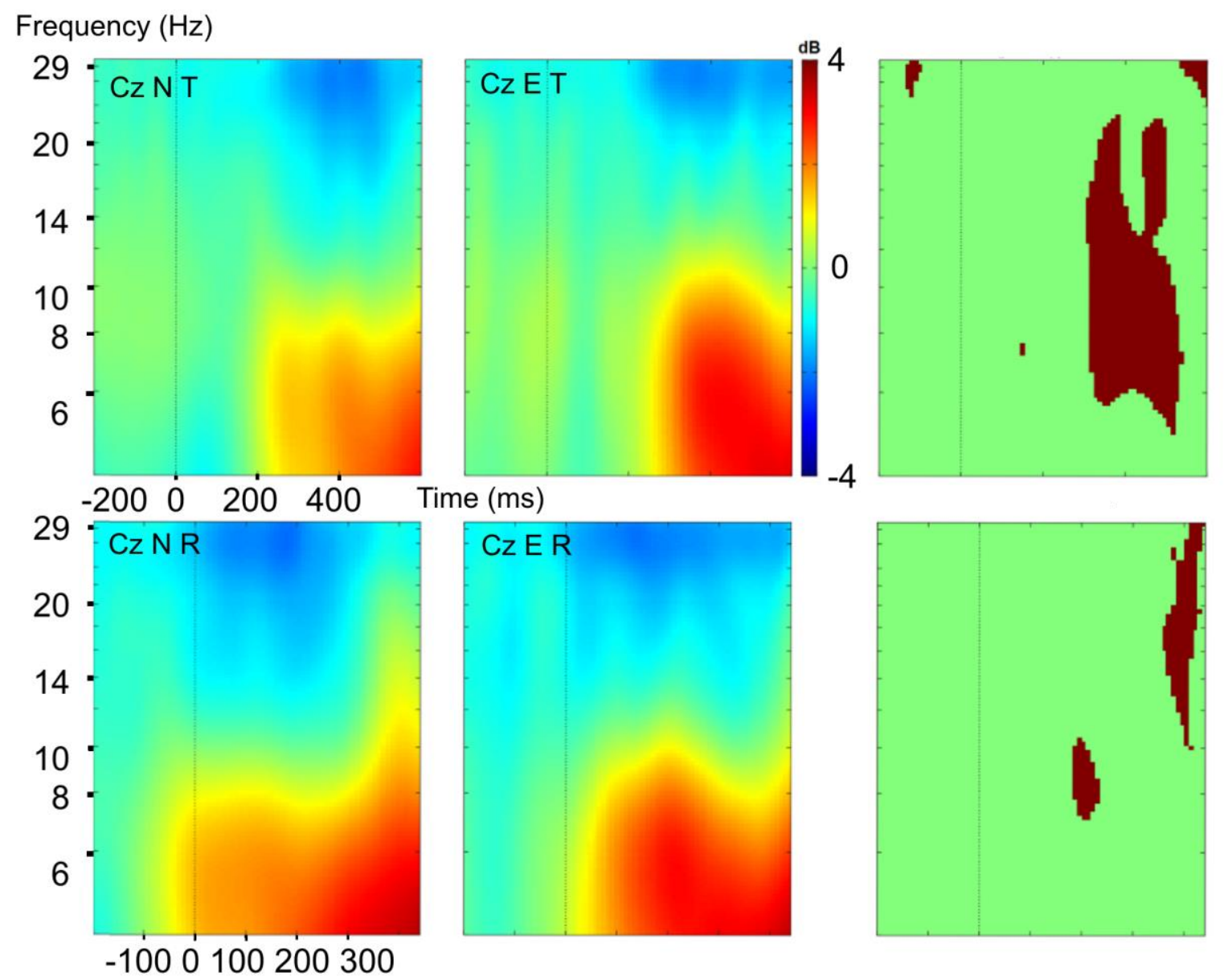

ERD/ERS in the different frequency bands over $C z$ in trials with a normal APA ( $N$ top row) or an APA error (E second row). The line indicates the target presentation time (target-locked: T) or TO (start of the APAs, response-locked: R). ERD is shown in blue, and ERS is shown in red in dB. We observed alpha ERS during APAs more intense for APA errors, beta ERD during the normal APA and during the APA error. This ERD was longer (target-locked, response-locked) and less intense (target-locked) in the low beta band for APA errors.

Figure 7. Source localization of cortical activity in the 0-600 ms time window. 


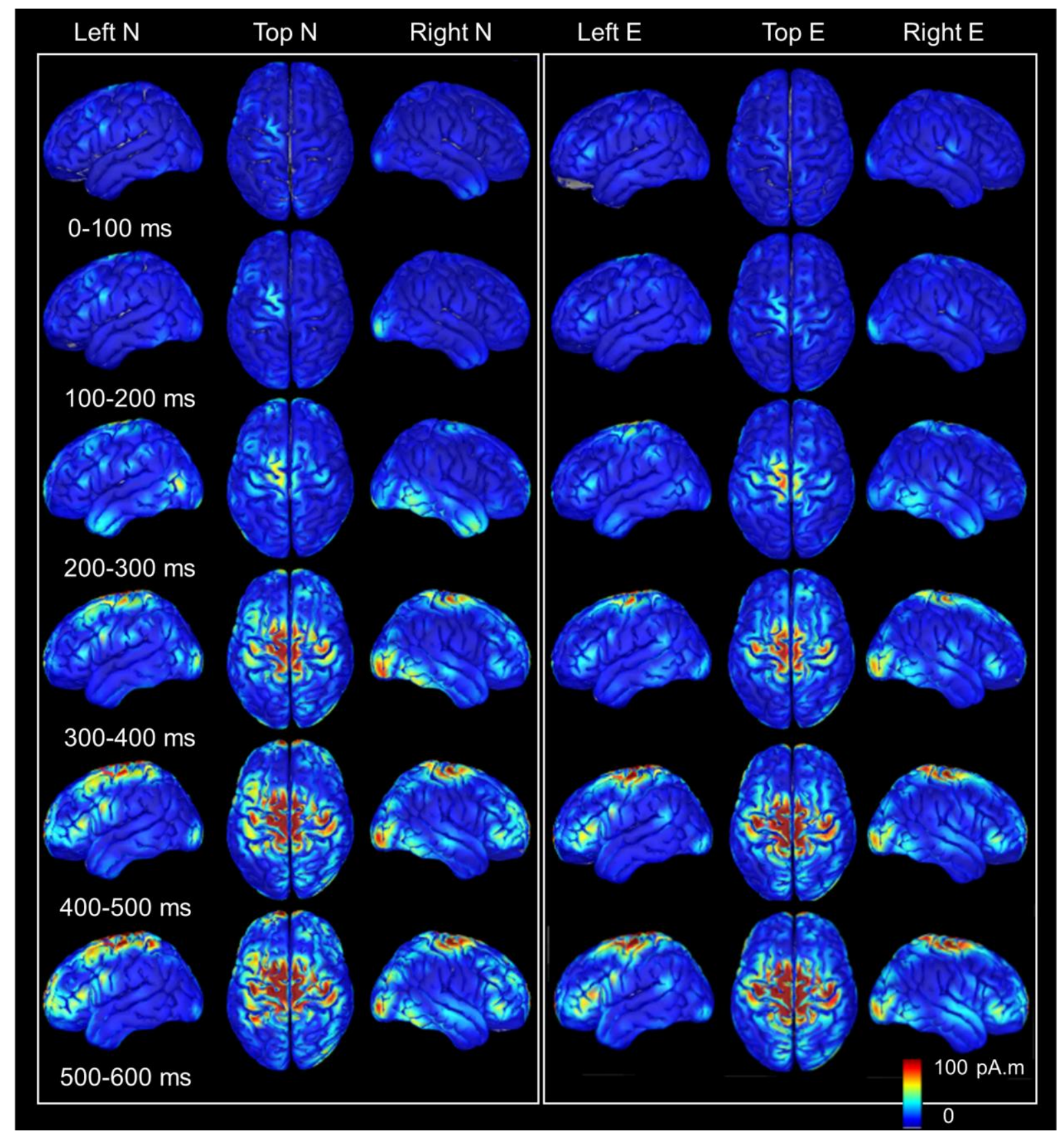

N: normal APAs; E: APA errors. The source localizations were the same in both conditions. 